\title{
Jaw, blink and corneal reflex latencies in multiple sclerosis
}

\author{
EACM SANDERS*, BW ONGERBOER DE VISSER $†$ EC BARENDSWAARD* \\ RJHM ARTS $\ddagger$
}

From the Departments of Neurology* and Clinical Neurophysiology $\ddagger$ of the University Hospital Leiden and St. Lucas Hospital and the University Hospital, Amsterdam, $\uparrow$ The Netherlands.

SUMMARY Jaw, blink and corneal reflexes, which all involve the trigeminal system, were recorded in 54 patients with multiple sclerosis; thirty-seven of these patients were classified as having definite multiple sclerosis and 17 as indefinite multiple sclerosis, according to Schumacher's criteria. The jaw reflex was abnormal less frequently than either of the other two reflexes, but in four cases it was the only abnormal reflex found. Testing a combination of two or three trigeminal reflexes did not yield a higher incidence of abnormalities than testing the blink or corneal reflex alone. Nine patients showed abnormal reflexes which were unexpected on the basis of clinical symptoms. The combined recordings demonstrate at least one abnormal reflex in $74 \%$ of the patients. The various types of reflex abnormalities reflect major damage to different parts of the trigeminal system and may therefore make an important contribution to the diagnosis of multiple sclerosis.

Recordings of the jaw, blink and corneal reflex provide information on electromyographic (EMG) performance at three different levels in the trigeminal system which extends from the most caudal brainstem area to the upper part of the midbrain.'

The afferent limb of the reflex loop whose performance is measured by the jaw reflex is thought to pass through the sensory root and the efferent limb through the motor root of the fifth nerve. ${ }^{23}$ Afferent nerve impulses in this reflex loop are related to the midbrain, probably to proprioceptive cells in the trigeminal mesencephalic nucleus which has collateral links with the motor nucleus in the pons. The blink reflex ${ }^{4}$ involves an early response (BR1) ipsilateral to the stimulated supraorbital nerve and a late bilateral response (BR2). The common afferent limb of the reflex loop in this case is formed by the sensory trigeminal root, while the facial nerve is the common efferent limb. The early response (BR1) is relayed centrally through an oligosynaptic arc in the

Address for reprint requests: BW Ongerboer de Visser, MD. Department of Clinical Neurophysiology, Academic Medical Centre, Meibergdreef 9,1105 A2-Amsterdam, the Netherlands.

Received 22 January 1985 and in revised form 27 March 1985. Accepted 5 April 1985 pons. Afferent fibres for BR2 descend from the pons to the spinal trigeminal tract. Nerve impulses are conducted from the most caudal area of the spinal trigeminal nucleus through polysynaptic medullary pathways, running both ipsilaterally and contralaterally, to the stimulated side of the face, before making connections with the facial nuclei. These trigemino-facial connections are thought to pass through the lateral reticular formation lying medial to the spinal trigeminal nucleus. ${ }^{5}$ The corneal reflex travels along the long ciliary nerve and utilises trigemino-facial pathways closely related to $\mathrm{BR} 2 .^{\circ}$ However, BR2 is conducted by a large fibre bundle of the supraorbital nerve while the small bundle of the long ciliary nerve mediates the corneal reflex.? Most studies on electromyographic (EMG) reflex recordings in multiple sclerosis concern blink reflex changes. ${ }^{8-15}$ Two studies relate to jaw reflexes ${ }^{1617}$ while data about corneal reflex latencies have not been published previously.

The present study concerns latency changes in the jaw, blink and corneal reflexes in 54 multiple sclerosis patients and their relation to clinically observed brainstem changes. We have also investigated which reflex or combination of reflexes yields most information about the involvement of the trigeminal system in patients with multiple sclerosis. 
Patients

Fifty-four patients, 36 female and 18 male, were studied. Their age at the time of the study varied from 21 to 59 years (mean 37.9$)$. Thirty-seven patients $(69 \%)$ had clinically definite multiple sclerosis and the other $17(31 \%)$ had indefinite multiple sclerosis, according to Schumacher's criteria. ${ }^{18}$ This patient group represents the total number of patients referred to the departments of Neurology and Clinical Neurophysiology at the University Hospital, Leiden and the St. Lucas Hospital, Amsterdam with suspected multiple sclerosis during the period 1982-1984.

On clinical examination all definite multiple sclerosis patients showed brainstem signs, mostly in combination with other signs and symptoms. Nine out of the 17 indefinite patients (53\%) showed clinical brainstem involvement. The brainstem signs and symptoms of our 54 patients could be assigned to the five clinical categories proposed by Kimura' as follows: (a) mesencephalic (IIIrd, IVth cranial nerve, $n=4)$; (b) pontine (internuclear ophthalmoplegia Vth, VIth or VIIth cranial nerve, $n=10$ ); (c) medullary (VIIIth, IXth, Xth cranial nerve, $n=4$ ); (d) more than one level of brainstem involvement, $(n=19)$; (e) undetermined level, $(n=9)$. Eight patients had no brainstem signs or symptoms. The duration of the disease at the time of the electrophysiological study ranged from 6 months to 21 years (mean 5.5 years). In all patients, the neurological examination was followed immediately by the EMG recordings.

\section{Methods}

Our method for studying jaw reflexes has been reported in a previous publication. ${ }^{19}$ Basically, a reflex hammer is used to tap a well defined spot on the patient's jaw and the electrical response in the masseter muscles is displayed on an oscilloscope screen. At the moment of the tap, a micro- switch in the reflex hammer triggers the time base of the oscilloscope. The electrical responses in both masseter muscles are picked up by surface or needle electrodes. The stored data for each test are later processed by computer to eliminate artefacts and to derive the exact time at which the evoked response starts. Consistent unilateral absence of the jaw reflex, a difference of more than $0.5 \mathrm{~ms}$ between the latencies on the two sides and bilateral absence of the reflex up to advanced ages are pathological findings.

The technique used to record the two components of the blink reflex has also been reported previously. ${ }^{2021}$ The responses from the lower half of both orbicularis oculi muscles are picked up by needle or suface electrodes, the latter having a passband extending from 30 to $1600 \mathrm{~Hz}$ and recorded simultaneously. A difference in latency time between the right and left sides exceeding $1.5 \mathrm{~ms}$ for BR1 and $8.0 \mathrm{~ms}$ for BR2 is considered abnormal. ${ }^{1}$ BR1 and BR2 are delayed if they exceed $13.0 \mathrm{~ms}$ and $41 \mathrm{~ms}$, respectively. Corneal reflexes are recorded as follows (for a more detailed description see ref 7): when a small metal sphere of diameter $2 \mathrm{~mm}$ makes contact with the cornea, there is reflex closure of the eyelids with a certain delay know as the corneal reflex latency. This sphere is connected to an electronic trigger circuit which has a bandpass extending from 30 to $1600 \mathrm{~Hz}$. Contact between cornea and metal ball causes a small current to flow from a current source through the trigger circuit triggering the time base of a dual-trace digital storage oscilloscope. The reflex response, measured as the voltage peak picked up by surface electrodes from the ipsilateral and contralateral orbicularis oculi muscles is displayed, on the storage oscilloscope. In this way, both the ipsilateral and the contralateral corneal reflex latencies can be read off. The ipsilateral reflex latency shows such a wide interindividual variation in normal subjects (30-64 ms) as not to provide a good diagnostic criterion. However, a latency difference of $8 \mathrm{~ms}$ or more between the ipsilateral and contralateral responses or of 10

Table 1 Distribution of single abnormal reflexes and the various combinations of abnormal reflexes in 54 multiple sclerosis patients (in 14 of these patients, all reflexes tested were normal).

\begin{tabular}{llll}
\hline EMG Component(s) & \multicolumn{2}{l}{ Number of patients with abnormality in: } & \\
\cline { 2 - 4 } & one reflex & two reflexes & three reflexes \\
\hline CR & 7 & & \\
BR1 & 2 & & \\
BR2 & 1 & & \\
JR & 4 & 6 & \\
CR + BR1 & & 3 & \\
CR + BR2 & & 3 & \\
CR + JR & & 1 & 4 \\
BR1 + JR & & 1 & 1 \\
BR1 + BR2 & & & \\
CR + BR1 + BR2 & & & \\
BR1 + BR2 + JR & & & \\
BR1 + CR + JR & & \\
CR + BR1 + BR2 + JR & & & \\
\hline
\end{tabular}

In this and subsequent tables,

BR1 = early blink reflex

$\mathrm{BR} 2$ = late blink reflex

$C R=$ corneal reflex

$\mathrm{JR}=$ jaw reflex. 


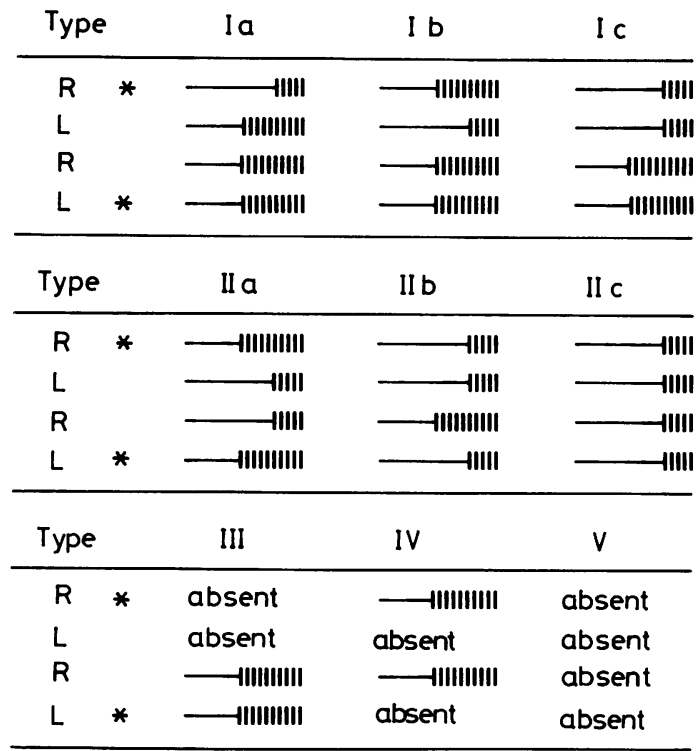

R Right side

$L$ Left side

* Side of stimulation

Figure Patterns of the five types of abnormal late blink and corneal reflexes in our patient group.

ms or more between the corresponding responses for the two eyes has been found to be considered as pathological.

The recorded data were subjected to statistical analysis with the aid of the SPSS software package. Associations between given two parameters are presented in contingency tables. The Chi-Square test with Yates correction was used to assess the significance of any associations found.

\section{Results}

The results of the electrophysiological reflex recordings are shown in table 1 . In this and further tables, the incidence of abnormal BR1s and BR2s are separated.

One isolated abnormal reflex was found in 14 patients $(26 \%)$. Two reflexes were abnormal in
Sanders, Ongerboer de Visser, Barendswaard, Arts another $14(26 \%)$, three in seven (13\%) and in five patients all four reflexes were abnormal. Fourteen patients $(26 \%)$ did not show any reflex disorder at all even though five of these had definite multiple sclerosis. An abnormally high BR1 latency was found unilaterally in nine patients and bilaterally in five. In another five patients BR1 was absent unilaterally while two patients showed no BR1 response after bilateral stimulation. The remaining three patients all showed a combination of a ipsilaterally absent and a contralaterally prolonged BR1 response. The jaw reflex was absent in seven patients and prolonged in nine (mean latency $10 \cdot 4 \pm$ $1.2 \mathrm{~ms}$ ).

The abnormal recorded BR2 and corneal reflexes could be divided into five different types (fig and table 2). Type 1 is divided into three subtypes, where the reflex is delayed ipsilaterally (Ia), contralaterally (Ib) and bilaterally (Ic) after stimulation on one side. Stimulation on the other side elicited bilaterally normal reflex responses in all type-1 patients. Type II is also divided into three subtypes, where the reflex latency is delayed contralaterally after stimulation on both sides (IIa), bilaterally after stimulation on one side and ipsilaterally after stimulation on the other side (IIb) and bilaterally after stimulation on both sides (IIc). Type III shows a complete bilateral absence of response after stimulation on one side whereas the reflex responses are bilaterally normal after stimulation on the other side. Type IV shows a normal ipsilateral and absent contralateral response to stimulation on one side and an absent ipsilateral and normal contralateral response to stimulation on the other side. In type $V$, all reflexes were absent after stimulation on both sides.

The incidence of all different types of single reflex abnormalities are summarised in table 3 . We see that the corneal reflex showed the highest frequency of abnormalities in both the definite $(63 \%)$ and indefinite patient group (35\%). A total of $32(68 \%)$ of the definite and eight (47\%) of the indefinite patients showed one or more reflex abnormalities. In the group as a whole, 40 patients $(74 \%)$ had at least one abnormal recorded reflex. We see further from table 3 that 37 of the 46 patients with brainstem signs and three of the eight patients without

Table 2 Incidence of the five types of abnormal late blink and corneal reflexes in our patient group.

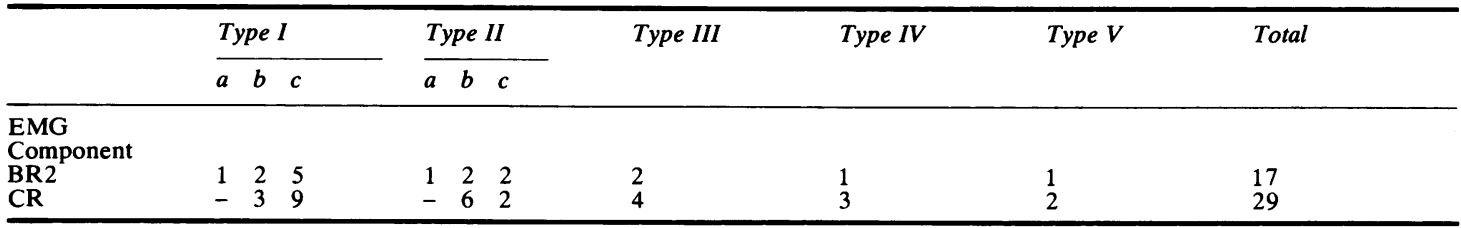


Table 3 Incidence of abnormal recorded reflexes in the patients with definite or indefinite multiple sclerosis, according to Schumacher's criteria.

\begin{tabular}{|c|c|c|c|c|c|c|c|c|}
\hline \multirow[t]{3}{*}{$\begin{array}{l}\text { Type of reflex } \\
\text { abnormalities }\end{array}$} & \multirow{2}{*}{\multicolumn{2}{|c|}{$\begin{array}{l}\text { Definite multiple sclerosis } \\
n=37 \\
\text { All patients had brainstem } \\
\text { signs }\end{array}$}} & \multicolumn{4}{|c|}{$\begin{array}{l}\text { Probable multiple sclerosis } \\
n=17\end{array}$} & \multirow{2}{*}{\multicolumn{2}{|c|}{$\begin{array}{l}\text { Total } \\
n=54\end{array}$}} \\
\hline & & & \multicolumn{2}{|c|}{ Brainstem signs $n=9$} & \multicolumn{2}{|c|}{ No brainstem signs $n=8$} & & \\
\hline & No & $\%$ & No & $\%$ & No & $\%$ & No & $\%$ \\
\hline $\begin{array}{l}\text { CR } \\
\text { BR1 } \\
\text { BR2 } \\
\text { JR }\end{array}$ & $\begin{array}{l}23 \\
20 \\
14 \\
12\end{array}$ & $\begin{array}{l}62 \\
54 \\
38 \\
32\end{array}$ & $\begin{array}{l}3 \\
3 \\
1 \\
2\end{array}$ & $\begin{array}{l}33 \\
33 \\
11 \\
22\end{array}$ & $\begin{array}{l}3 \\
2 \\
2 \\
2\end{array}$ & $\begin{array}{l}37 \cdot 5 \\
25 \\
25 \\
25\end{array}$ & $\begin{array}{l}29 \\
25 \\
17 \\
16\end{array}$ & $\begin{array}{l}58 \\
46 \\
31 \\
30\end{array}$ \\
\hline Total & 32 & 86 & 5 & 56 & 3 & $37 \cdot 5$ & 40 & 74 \\
\hline
\end{tabular}

brainstem impairment, had one or more reflex abnormalities. Statistical analysis showed that neither reflex abnormality in the individual tests, nor an abnormal result in all tests combined provide a reliable indicator for definite multiple sclerosis.

We also investigated the more detailed relationship between abnormal results in the different reflex tests and clinical signs of involvement of the various brainstem levels. Thirteen out of the 18 patients with mesencephalic, pontine or medulla oblongata impairment showed an abnormal reflex involving the brainstem level indicated by the clinical signs. The other five patients showed a reflex abnormality not related to the clinical signs. Only seven out of the 19 patients with clinical signs related to two or three brainstem levels showed two or three abnormal reflexes, whereas 11 showed one reflex abnormality and one showed no reflex abnormality at all. Only one of nine patients with brainstem signs of undetermined localisation had an abnormal reflex response (corneal reflex).

Associations between reflex parameters pairwise are summarised table 4. Abnormal corneal reflexes show a statistically significant association with BR1 $(p=0.0675)$ and BR2 $(p=0.045)$ disorders and with the combination of these two reflex abnormalities $(p=0.012)$. None of the other associations was statistically significant. Finally table 5 gives an impression of the diagnostic efficacy of the various tests.

Table 4 Correlations between the various recorded brainstem reflexes.

\begin{tabular}{|c|c|c|c|c|c|c|c|c|c|}
\hline & \multicolumn{2}{|c|}{$B R 1$} & \multicolumn{2}{|c|}{$B R 2$} & & \multicolumn{2}{|c|}{$B R 1+B R 2$} & \multicolumn{2}{|c|}{$J R$} \\
\hline & + & - & + & - & & + & - & + & - \\
\hline $\begin{array}{l}\text { CR+ } \\
\text { CR- } \\
\text { JR+ } \\
\text { JR- }\end{array}$ & \multicolumn{2}{|c|}{$\begin{array}{lc}15 & 14 \\
6 & 19 \\
0.05<p<0.01\end{array}$} & \multicolumn{2}{|c|}{$\begin{array}{cr}12 & 17 \\
4 & 21 \\
p_{7}= & 0.045 \\
9 & 9 \\
p=0.369(\mathrm{NS})\end{array}$} & & \multicolumn{2}{|c|}{$\begin{array}{lr}19 & 10 \\
7 & 18 \\
p=0.012 & \\
8 & 7 \\
17 & 21 \\
p= & 0.635(\mathrm{NS})\end{array}$} & \multicolumn{2}{|c|}{$\begin{array}{l}9 \\
7 \\
p=0.556(N S)\end{array}$} \\
\hline \multicolumn{10}{|c|}{$\begin{array}{l}+=\text { abnormal }-=\text { normal } \\
p=\text { statistical level of significance of association of the two parameters considered. }\end{array}$} \\
\hline \multicolumn{10}{|c|}{$\begin{array}{l}\text { Table } 5 \text { Cummulative frequencies of the reflex abnormalities detected by single tests or by combinations of two or three } \\
\text { tests. }\end{array}$} \\
\hline \multirow[t]{3}{*}{ Electromyographic test } & & \multicolumn{8}{|c|}{ Frequency* } \\
\hline & & \multicolumn{3}{|c|}{$\begin{array}{l}\text { definite } \\
n=37\end{array}$} & \multicolumn{3}{|c|}{$\begin{array}{l}\text { probable } \\
n=17\end{array}$} & \multicolumn{2}{|c|}{$\begin{array}{l}\text { total } \\
n=54\end{array}$} \\
\hline & & No & & & No & & $\%$ & No & $\%$ \\
\hline $\begin{array}{l}\text { CR } \\
\text { BR1 }+ \text { BR2 }\end{array}$ & & $\begin{array}{l}23 \\
21 \\
12\end{array}$ & & & $\begin{array}{l}6 \\
5 \\
4\end{array}$ & & $\begin{array}{l}35 \\
29 \\
24\end{array}$ & $\begin{array}{l}29 \\
26 \\
16\end{array}$ & $\begin{array}{l}58 \\
48 \\
30\end{array}$ \\
\hline $\mathrm{JR}+\mathbf{C R}$ & & 29 & & & 7 & & 41 & 36 & 67 \\
\hline $\begin{array}{l}\mathrm{BR} 1+\mathrm{BR} 2+\mathrm{CR} \\
\mathrm{BR} 1+\mathrm{BR} 2+\mathrm{JR}\end{array}$ & & $\begin{array}{l}29 \\
27\end{array}$ & & & $\begin{array}{l}7 \\
6\end{array}$ & & $\begin{array}{l}41 \\
35\end{array}$ & $\begin{array}{l}36 \\
33\end{array}$ & $\begin{array}{l}67 \\
61\end{array}$ \\
\hline $\mathrm{BR} 1+\mathrm{BR} 2+\mathrm{JR}+\mathrm{Cl}$ & & 32 & & & 8 & & 47 & 40 & 74 \\
\hline
\end{tabular}

*This is the frequency of abnormal results in the test or test combination in question, in the patient population with clinically definite or probable multiple sclerosis. 


\section{Discussion}

There are two questions to which we might hope to get an answer from the tests dealt with in this paper: 1 . Do these tests, taken singly or in combination, provide reliable means of diagnosing extra lesions in patients suspected of multiple sclerosis?

2. Can these tests help us to gain more detailed knowledge of brainstem involvement in a patient with multiple sclerosis?

Briefly the answer to the first question is "no" and to the second one "yes". We will amplify on these two answers in this discussion. As will be seen from the results presented above (in particular table 5), none of the EMG tests considered in this paper, nor any combination of these tests, gives a totally reliable indication that a given patient has multiple sclerosis. The most highly indicative single test is the corneal reflex test, which gave positive (abnormal) results in $58 \%$ of the multiple sclerosis patients we examined. Even when all four tests are considered together, table 5 shows that only $74 \%$ of our patients gave a positive result in one or more of these tests. Fourteen out of our 54 patients had no reflex abnormality'; five $(14 \%)$ of these in the definite multiple sclerosis class, four $(44 \%)$ in the class characterised by indefinite multiple sclerosis with clinical signs of brainstem involvement and five $(62,5 \%)$ in the class characterised by indefinite multiple sclerosis without signs of brainstem involvement. Thus we see that the chance of getting a positive result in one of our tests does increase roughly in line with the weight of clinical evidence for multiple sclerosis. We may conclude that, in the present state of knowledge, there is no question of a suitable combination of EMG tests, always replacing clinical examination as a primary diagnostic tool to establish brainstem involvement in patients suspected of multiple sclerosis. This conclusion could perhaps be called disappointing. Nevertheless, the answer to question 2 above is sufficiently positive to justify recommending the inclusion of a battery of EMG tests in the examination of patients with suspected multiple sclerosis. The results of these tests can definitely yield a more differentiated picture of the brainstem involvement caused by the demyelinating process. Let us consider some of the various ways in which this clarification can be obtained.

First of all, it may be noted that the jaw reflex test is in a certain sense of particular diagnostic significance, as it provides information about brainstem involvement at the segmental level which cannot be obtained by clinical means. It is then perhaps surprising at first sight that this test yielded abnormal results less often than any of the other tests considered in this paper. This may however prob- ably be explained by the fact that the reflex pathways involved in the jaw reflex are less extensive than those involved in the blink reflex and corneal reflexes. Still, in four of our patients the jaw reflex was the only one found to be abnormal. This agrees with findings in similar populations of multiple sclerosis patients by Yates and Brown. ${ }^{17}$

A further interesting finding was that our recordings of the corneal and blink reflexes revealed a silent lesion in three patients with indefinite multiple sclerosis and without clinical brainstem involvement. In six patients with brainstem impairment on the other hand, the EMG test results did not correlate with the clinical findings.

With regard to the various types of late blink and corneal reflex abnormalities, the location of the major damage to the trigeminal reflex system may be deduced from anatomical findings derived previously from patients with vascular lesions. ${ }^{1256}$ Types Ia, Ib, Ic, III and IV imply a unilateral location of the brainstem lesions and types II and V a bilateral location. Further, types III, IV and V imply blocking of impulses and hence reflect more severe damage than types I and II, which imply incomplete conduction impairment. In type Ia (where the reflex response is delayed ipsilaterally) and type Ib (where the response is delayed contralaterally to the stimulated side), impulses ascending to the facial nucleus are impaired by a lesion probably situated in the lateral reticular formation. In type Ic (with bilaterally delayed afferent response) the lesion involves the afferent limb which passes through the descending spinal trigeminal tract. In type IIa only contralateral responses are delayed by injury, presumably located on the midline of the lower brainstem. In type IIb (which can be regarded as a composite of type Ia and Ic) the lesions may be expected to be in the lateral reticular formation on one side and in the descending trigeminal tract on the other. Type IIc shows a bilateral afferent block on both sides. In type IV (where contralateral responses are blocked upon stimulation of one side and ipsilateral responses on stimulation of the other) the lesion must involve the lateral reticular formation along which both contralateral and ipsilateral impulses are mediated to the facial nucleus. Type $V$ represents the most severe damage, with a complete bilateral absence of reflex responses. It is presumbably due to afferent blocks in the spinal trigeminal tracts or diffuse lesions in the lower brainstem. Both the association between abnormal corneal and blink reflexes and the lack of an association between abnormalities of these two reflexes and the jaw reflex (table 4) may be explained by anatomical considerations. Both the corneal and blink reflex pathways enter the pons via the ophthalmic division, while the afferent limb of 
the jaw reflex pathway runs through the mandibular division of the fifth nerve and the efferent limb through the motor root. Centrally, the fibres for the jaw reflex pathway run largely through the upper brainstem, the BR1 through the pons and for BR2 and the corneal reflex through the lower brainstem. This makes it clear that the jaw reflex pathway has fewer topographical links with the blink reflexes than the latter two have with each other.

The authors are indebted to Dr RH Bathgate (Eindhoven) for critically reviewing this paper. Mrs Ch J Th Sanders-Bozon prepared the manuscript.

\section{References}

' Ongerboer de Visser BW. Anatomical and functional organization of reflexes involving the trigeminal system in man: jaw reflex, blink reflex, corneal reflex and exteroceptive suppression. In: Desmedt JE, ed. Motor control mechanisms in health and disease. New York: Raven Press, 1983:727-38.

${ }^{2}$ Ongerboer de Visser BW. Afferent limb of the human jaw reflex: electrophysiologic and anatomic study. Neurology (NY) 1982;32:563-6.

${ }^{3}$ Ferguson JT. Electrical study of jaw and orbicularis oculi reflexes after trigeminal surgery. J Neurol Neurosurg Pyschiatry 1975;41:819-23.

${ }^{4}$ Kugelberg E. Facial reflexes. Brain 1952;75:385-96.

s Ongerboer de Visser BW, Kuypers HGJM. Late blink reflex changes in lateral medullary lesions: an electrophysiological and neuroanatomical study of Wallenberg's syndrome. Brain 1978;101:285-94.

- Ongerboer de Visser BW, Moffie D. Effects of brainstem and thalamic lesions on the corneal reflex: an electrophysiological and anatomical study. Brain 1979; 102: 595-608.

${ }^{7}$ Ongerboer de Visser BW, Mechelse K, Megens PHA. Corneal reflex latency in trigeminal nerve lesions. Neurology (Minneap) 1977;27:1164-7.

${ }^{8}$ Namerow NS, Etemadi A. The orbicularis oculi reflex in multiple sclerosis. Neurology

(Minneap) 1970;20:1200-3.

${ }^{9}$ Kimura J. Electrically elicited blink reflex in diagnosis of multiple sclerosis. Brain 1975;98:413-26.
${ }^{10}$ Lowitzsch K, Kuhnt U, Sakmann Ch, et al. Visual pattern evoked responses and blink reflexes in assessment of MS diagnosis. J Neurol 1976;213:17-32.

"Laquaniti F, Benna P, Gilli M, Troni W, Bergamasco B. Brainstem auditory evoked potentials and blink reflex in quiescent multiple sclerosis. Electroencephalogr Clin Neurophysiol 1979;47:607-10.

${ }^{12} \mathrm{Kjaer} \mathrm{M}$. The value of brainstem auditory, visual and somatosensory evoked potentials and blink reflexes in the diagnosis of multiple sclerosis. Acta Neurol Scand 1980;62:220-36.

${ }^{13}$ Koshbin S, Hallett M. Multimodality evoked potentials and blink reflex in multiple sclerosis. Neurology $(N Y)$ 1981;31:138-44.

${ }^{14}$ Tackman W, Strenge H, Barth R, Sojka-Raytscheff A. Evaluation of various brainstructures in multiple sclerosis with multimodality evoked potentials, blink reflex and nystagmography. J Neurol 1980;224:3346.

15 Yates SK, Brown WF. Light-stimulus evoked blink: Methods, normal values, relation to other blink reflexes and observations in multiple sclerosis. Neurology (NY) 1981;31:272-81.

${ }^{16}$ Goodwill CJ, O'Tuama L. Electromyographic recording of the jaw reflex in multiple sclerosis. J Neurol Neurosurg Psychiatry 1969;32:6-10.

17 Yates SK, Brown WF. The human jaw jerk: Electromyographic methods to measure the latency, normal values and changes in multiple sclerosis. Neurology (NY) 1981;31:632-4.

${ }^{18}$ Schumacher GA, Beebe G, Kibler RF, et al. Problems of experimental trials of therapy in multiple sclerosis. Report by the panel on the evaluation of experimental trials of therapy in multiple sclerosis. Ann NY Acad Sci 1965;22: 522-68.

${ }^{19}$ Ongerboer de Visser BW, Goor C. Jaw reflexes and masseter electromyograms in mesencephalic and pontine lesions. An electro-diagnostic study. J Neurol Neurosurg Psychiatry 1976;39:90-2.

${ }^{20}$ Ongerboer de Visser BW, Goor C. Electromyographic and reflex study in idiopathic and symptomatic trigeminal neuralgias; latency of the jaw and blink reflexes. $J$ Neurol Neurosurg Psychiatry 1974;37:1225-30.

${ }^{21}$ Kimura J. In: Kimura J, ed. Electrodiagnosis in diseases of nerve and muscle: principles and practice. Philadelphia: FA Davis, 1983:331-2. 